\title{
Review on the Fire Resistance and Pumpability Performance of Fiber Reinforced High Strength Concrete
}

\author{
Kwon, Hae-Won* Kim, Young-Su \\ Department of Architectural Engineering, Pusan National University, Geumjeong-Gu, Busan, 609-735, Korea
}

\begin{abstract}
Currently, many high-rise buildings are built in Korea for land-efficient utilization and vista. In high-rise buildings this tall, the use of high-strength concrete is essential to reduce the cross-section of structure members and secure axial load. However, this high strength concrete is vulnerable to spalling by fire, due to the water vapor pressure caused by the very high temperature in fire. To prevent this, the main method used is to reinforce the concrete with fiber. However, there has been little research on the pumpability of fiber reinforced high strength concrete. For this reason, this study features a performance review based on the properties and pumpability of fiber reinforced high strength concrete. In addition, the parameter of rheology was measured by extracting mortar from the concrete, and friction factor was measured through a $400 \mathrm{~m}$ horizontal pipe pumping test using the fiber reinforced high strength concrete. The basic information on fiber reinforced high strength concrete that we obtain through the experiments and review will contribute to the field.
\end{abstract}

Keywords : fire resistance, fiber reinforced high strength concrete, pumpability

\section{Introduction}

To effectively utilize Korea's limited land and secure a fine view, a number of high-rise buildings have been built. High strength concrete has been widely applied to high-rise buildings to reduce the section of structural members and secure axial load.

However, with the section of structural members lost by spalling resulting from the fire, high strength concrete can have a seriously adverse impact on the safety of structures. For this reason, the Ministry of Land, Transport, and Maritime Affairs announced the "Fire Resistance Performance Management Criteria for High Strength Concrete Columns and Beams (No.

Received : October 10, 2012

Revision received : December 7, 2012

Accepted : December 24, 2012

* Corresponding author : Kwon, Hae-Won

[Tel: 010-9798-8325, E-mail: goodjaya@naver.com]

(c)2013 The Korea Institute of Building Construction, All rights reserved.
2008-334)," and the domestic construction industry has made efforts to develop diverse technologies to secure the fire resistance performance of high strength concrete[1,2.3].

On the other hand, according to previous studies, as a technology to secure fire resistance performance of high strength concrete, adding synthetic fiber was found to be effective for preventing spalling as it reduced the vapor pressure within concrete during fire[4,5,6,]. But there have been few studies on the pumpability and basic physical properties of polylon fiber, a synthetic fiber of polypropylene and nylon that is currently in wide use.

Therefore, the basic physical properties of fiber reinforced high strength concrete and fire resistance performance were reviewed, the plastic viscosity of mortar extracted from the concrete was compared, and the friction factor of high strength concrete using horizontal pumping pipes was verified. This paper aims to provide fundamental data on the 
application of fiber reinforced high strength concrete to construction sites[7,8].

\section{Experiment plan and method}

\subsection{Experiment plan}

The experiment scheme is indicated in Table 1. The basic physical properties of $50 \mathrm{MPa}$ and $60 \mathrm{MPa}$ high strength concrete are examined in Series I, and the fire resistance of fiber reinforced high strength concrete set based on the basic physical properties examined in Series I is assessed in Series II.

In addition, to examine and compare the pumpability performance of fiber reinforced concrete and Plain in Series III and IV, the plastic viscosity of the mortar extracted from each concrete is compared based on shear rate and shear stress in Series III. $0.05 \%$ of fiber is added to the $50 \mathrm{MPa}$ and $60 \mathrm{MPa}$ high strength concrete to make fiber reinforced concrete. In addition, in Series IV the friction factor is calculated by measuring pumpability pressure and concrete discharge velocity, in order to understand the friction factor of the concrete.

Through Series I, II, III, and IV, this paper aims to secure fundamental data on the application of fiber reinforced high strength concrete to construction sites.

\subsection{Experiment method}

Table 1. Experimental scheme

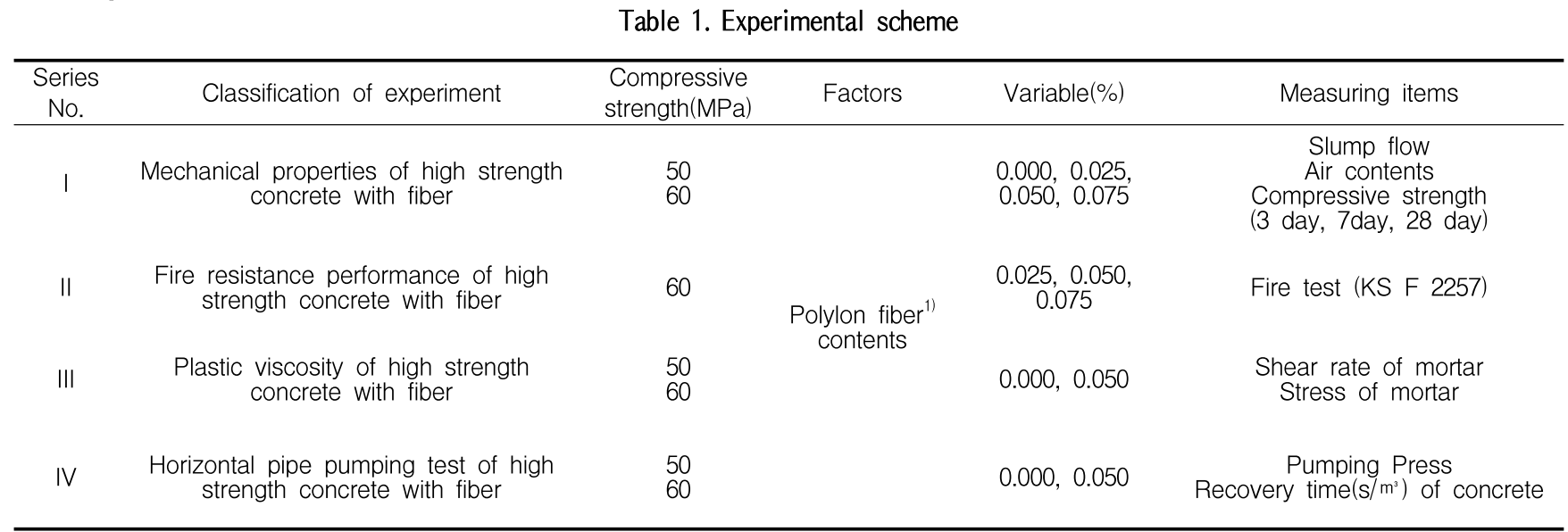

1) Polylon fiber : Volume ratio $1: 1$ of Poly propylene(length: $19 \mathrm{~mm}$ ) and Nylon(length: $12 \mathrm{~mm})$ Fiber
To examine performance in Series I, the fiber reinforced high strength concrete is tested to assess basic physical properties in compliance with the evaluation items stipulated in $\mathrm{KS}$, and the test materials used are indicated in Table 2.

Table 2. Physical properties of high strength concrete

\begin{tabular}{|c|c|c|c|c|c|c|c|c|c|c|}
\hline \multirow{2}{*}{\multicolumn{2}{|c|}{$\begin{array}{c}\text { Classification } \\
\left(\mathrm{F}_{\mathrm{ck}}(\mathrm{MPa}),\right. \\
\text { Fiber contents })\end{array}$}} & \multirow{2}{*}{$\begin{array}{l}\text { W/B } \\
(\%)\end{array}$} & \multirow{2}{*}{$\begin{array}{l}\text { S/a } \\
(\%)\end{array}$} & \multicolumn{6}{|c|}{ Unit weight $\left(\mathrm{kg} / \mathrm{m}^{3}\right)$} & \multirow{2}{*}{$\begin{array}{l}\text { Polylon } \\
\text { fiber } \\
\left(\mathrm{g} / \mathrm{m}^{3}\right)\end{array}$} \\
\hline & & & & W & OPC & \multicolumn{2}{|c|}{ Srive Scru } & G & $A D$ & \\
\hline \multirow{4}{*}{50} & $0.000(\%)$ & \multirow{4}{*}{29.5} & \multirow{4}{*}{45.5} & \multirow{4}{*}{165} & \multirow{4}{*}{560} & \multirow{4}{*}{453} & \multirow{4}{*}{300} & \multirow{4}{*}{915} & \multirow{4}{*}{4.48} & 0.0 \\
\hline & $0.025(\%)$ & & & & & & & & & 257.5 \\
\hline & $0.050(\%)$ & & & & & & & & & 515.0 \\
\hline & $0.075(\%)$ & & & & & & & & & 772.5 \\
\hline \multirow{4}{*}{60} & $0.000(\%)$ & \multirow{4}{*}{27.5} & \multirow{4}{*}{44.0} & \multirow{4}{*}{165} & \multirow{4}{*}{600} & \multirow{4}{*}{497} & \multirow{4}{*}{213} & \multirow{4}{*}{914} & \multirow{4}{*}{4.80} & 0.0 \\
\hline & $0.025(\%)$ & & & & & & & & & 257.5 \\
\hline & $0.050(\%)$ & & & & & & & & & 515.0 \\
\hline & $0.075(\%)$ & & & & & & & & & 772.5 \\
\hline
\end{tabular}

In addition, to perform fire resistance performance test in Series II, fiber reinforced specimens (by adding polylon fiber by volume ratio $(0.023 \%$, $0.050 \%$, 0.075\%) were manufactured at the dimensions of $1000 \times 1350 \times 1500 \mathrm{~mm}$ with $40 \mathrm{~mm}$ of cover concrete thickness, where sensors were embedded on the main reinforced bar as shown in Figure 1 in compliance with No. 2008-334 Fire Resistance Performance Management Criteria for High Strength Concrete Columns and Beams announced by the Ministry of Land, Transport and 
Maritime Affairs. Tests were conducted in horizontal furnace at the highest attainable temperature of $1100^{\circ} \mathrm{C}$ for three hours as shown in Figure 2 based on the standard time-temperature curve presented in KS F 2257-1 Methods of fire resistance test for elements of building construction-General requirements.

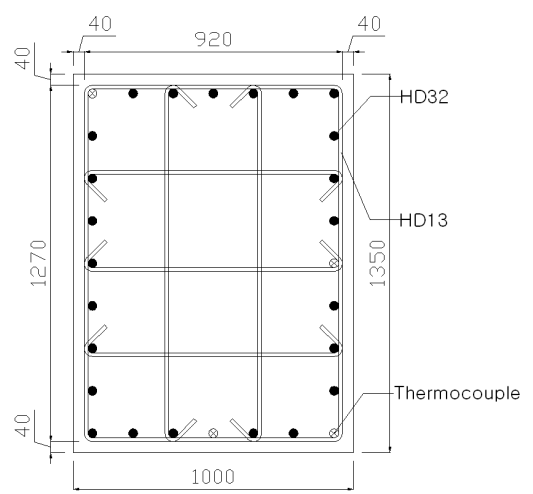

Figure 1. Cross section of fire resistance test specimen

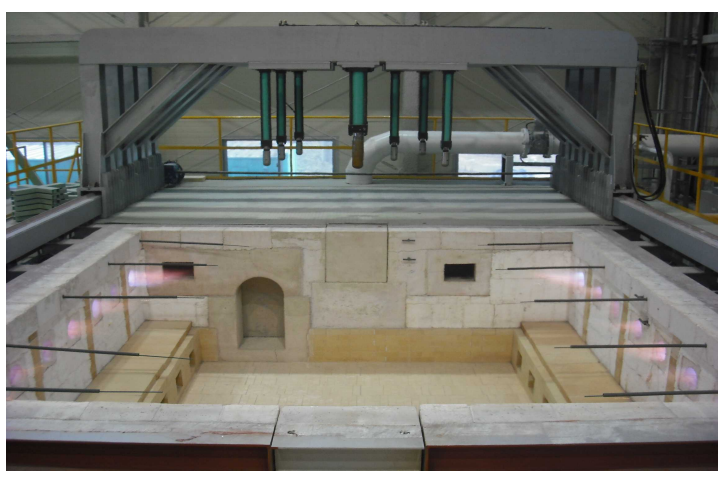

Figure 2. Fire test of high strength concrete

To examine pumpability performance of fiber reinforced high strength concrete in Series III, of the rheological properties, plastic viscosity was verified by measuring shear rate and shear stress using a rheometer shown in Figure 4 under the assumption that mortar extracted from high strength concrete is fluid, as shown in Bingham model equation (1) and Figure 3.

$$
\tau=\tau_{0}+\mu \dot{\gamma}
$$

Here,

$$
\begin{array}{ll}
\tau & : \operatorname{shear} \operatorname{stress}(\mathrm{Pa}) \\
\tau_{0} & : \text { yield } \operatorname{stress}(\mathrm{Pa}) \\
\mu & : \operatorname{plastic} \operatorname{viscosity}(\mathrm{Pa} . \mathrm{s}) \\
\dot{\gamma} & : \operatorname{shear} \operatorname{rate}(1 / \mathrm{s})
\end{array}
$$

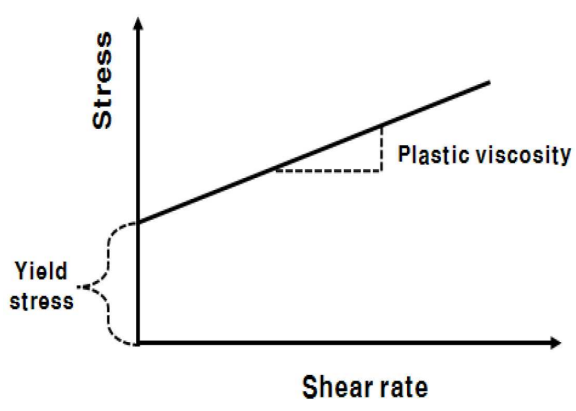

Figure 3. Shear rate and stress

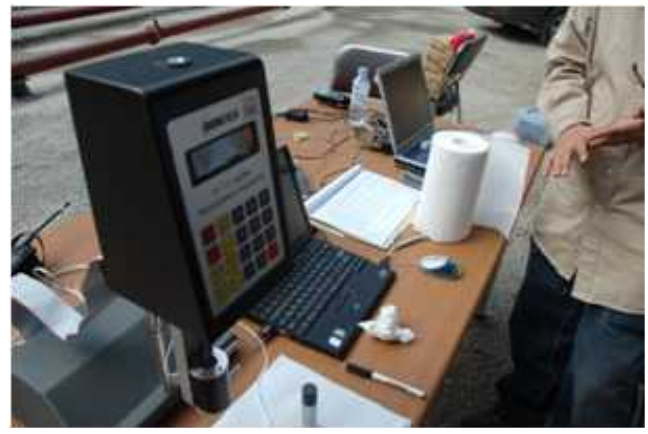

Figure 4. Rheometer(Brookfield DV-III)

Unlike the assumption set in Series III, since concrete is three- or more-phase composites and a heterogeneous mixture, the pressure loss caused by concrete itself at the pipe should be examined. Therefore, in Series IV, pumping time of concrete discharged to a container was measured using a 400m-long horizontal pipe and a fixed pumping car. The horizontal pipe was planned as shown in Figure 5. The pipe pressure was measured in a cycle of 60 $\mathrm{Hz}$ through a dynamic logger at every $100 \mathrm{~m}$ interval from the pumping car.

At this time, the friction factor was calculated by applying given pressures to a discharging velocity in Equation (2) derived through Beroulli' s principle and force equilibrium theory, through which the 
pumpability performance of the fiber reinforced high strength concrete was examined[8,9,10].

$$
\begin{aligned}
& \Delta P=P_{1}+P_{2}+P_{3} \\
= & \left(\lambda \frac{l}{d} \times \frac{v^{2}}{2 g} \times \gamma\right)+\left(\zeta \frac{v^{2}}{2 g} \times \gamma\right)+(h \times \gamma)---(2)
\end{aligned}
$$

Here

$\Delta P:$ pressure of the pump $\left(\mathrm{kgf} / \mathrm{m}^{2}\right)$

$P_{1}$ : friction loss within the pipe $\left(\mathrm{kgf} / \mathrm{m}^{2}\right)$

$P_{2}$ : local pressure loss $\left(\mathrm{kgf} / \mathrm{m}^{2}\right)$

$P_{3}$ : pressure loss by height $\left(\mathrm{kgf} / \mathrm{m}^{2}\right)$

$\lambda \quad$ : friction factor

$l \quad$ : vertical length of the pump(m)

$d$ : diameter of the pipe $(\mathrm{m})$

$v:$ flow velocity $(\mathrm{m} / \mathrm{s})$

$g \quad$ : gravity acceleration $(9.8 \mathrm{~m} / \mathrm{s} 2)$

$\gamma \quad$ : specific weight $\left(\mathrm{kgf} / \mathrm{m}^{3}\right)$

$\zeta$ : local friction resistance factor

$h \quad$ : vertical height of the pipe(m)

\section{Review of test results and analysis}

\subsection{Test results of basic physical properties of concrete}

Through the tests of the basic physical properties of fiber reinforced high strength concrete, the fiber reinforced concrete was found to have a similar slump flow, air content, and compressive strength to Plain, from which it was verified that fiber had no great impact on the physical performance of concrete.

\begin{tabular}{|c|c|c|c|c|c|c|}
\hline \multirow{2}{*}{\multicolumn{2}{|c|}{$\begin{array}{l}\text { Classification } \\
\left(F_{c k}(\mathrm{MPa})\right. \\
\text { Fiber contents })\end{array}$}} & \multicolumn{2}{|c|}{$\begin{array}{c}\text { Fresh concrete } \\
\text { properties }\end{array}$} & \multicolumn{3}{|c|}{$\begin{array}{l}\text { Compressive } \\
\text { strength(MPa) }\end{array}$} \\
\hline & & $\begin{array}{c}\text { Slump } \\
\text { flow }(m m)\end{array}$ & $\begin{array}{c}\text { Air } \\
\text { Contents(\%) }\end{array}$ & 3 day & 7 day & 28 day \\
\hline \multirow{4}{*}{50} & $0.000(\%)$ & $700 / 680$ & 4.3 & 41.6 & 46.2 & 61.1 \\
\hline & $0.025(\%)$ & 680/670 & 4.3 & 42.3 & 46.9 & 62.2 \\
\hline & $0.050(\%)$ & 690/690 & 4.3 & 41.1 & 47.7 & 61.9 \\
\hline & $0.075(\%)$ & 690/680 & 4.5 & 40.8 & 46.5 & 60.6 \\
\hline \multirow{4}{*}{60} & $0.000(\%)$ & $700 / 680$ & 4.5 & 51.7 & 59.6 & 72.4 \\
\hline & $0.025(\%)$ & $680 / 680$ & 4.3 & 51.2 & 61.0 & 71.8 \\
\hline & $0.050(\%)$ & 690/680 & 4.7 & 50.7 & 57.8 & 71.5 \\
\hline & $0.075(\%)$ & 690/670 & 4.7 & 50.9 & 58.5 & 70.3 \\
\hline
\end{tabular}

Table 3. Physical properties of high strength concrete

\subsection{Results of fire resistance performance test of concrete}

Through the fire resistance performance tests of high strength concrete according to mix proportion of fiber, it was verified that the more fiber was mixed, the lower the average and highest

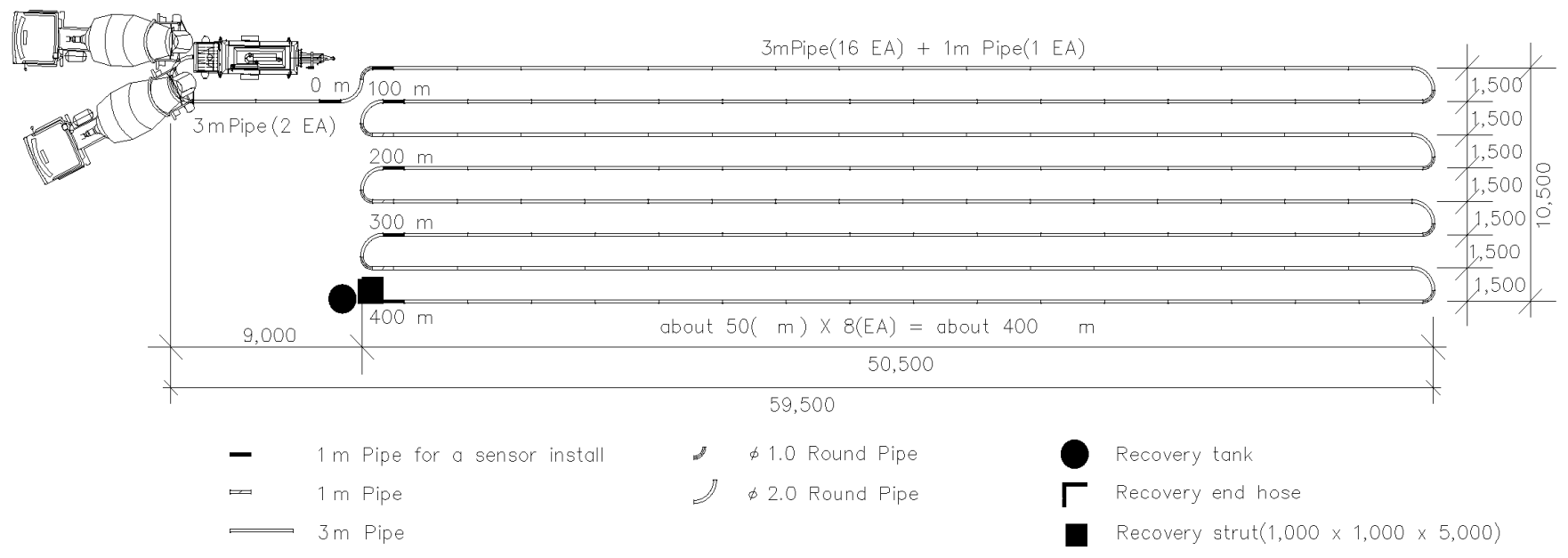

Figure 5. Experimental plan of concrete pumpability 
temperature of the main reinforced bar, as shown in Figures 6 and 7.

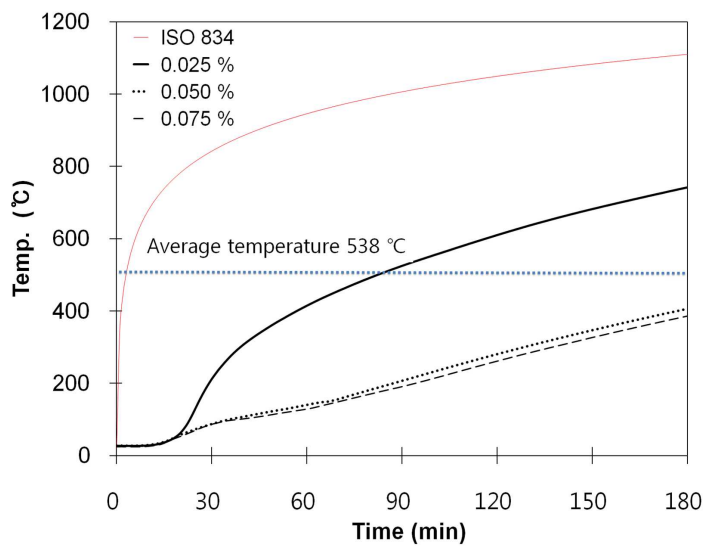

Figure 6. Fire test result by fiber content(\%) I

(Average temperature)

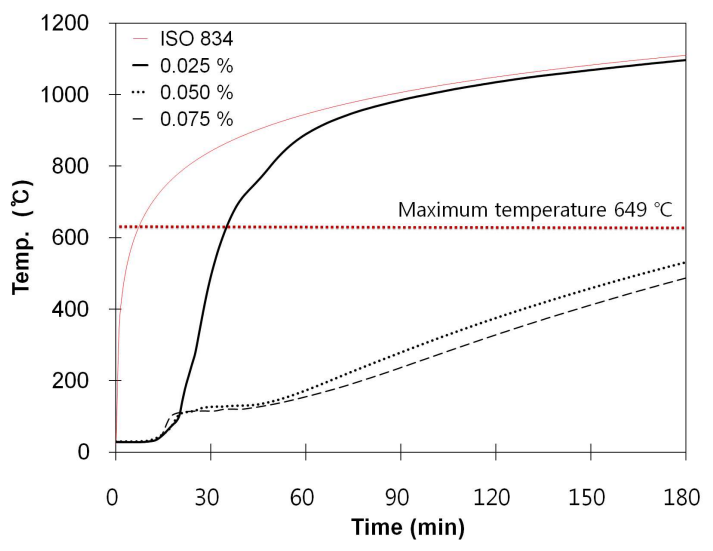

Figure 7. Fire test result by fiber content(\%) ॥

(Maximum temperature)

Temperature was observed to start to rise gradually at 20 minutes in the specimens with $0.05 \%$ and $0.075 \%$ of fiber; however, the temperature rise of the main reinforced bar was observed to be slow at $100^{\circ} \mathrm{C}$. It is believed the moisture within the concrete was discharged through the channel generated by the fusion of polypropylene and nylon fiber consisting of the polylon fiber, which slowed the temperature rise $[4,5]$.

In addition, the specimens with $0.05 \%$ and $0.075 \%$ of fiber met the fire resistance criteria at the completion of the 3-hour fire resistance test. However, the specimen with $0.025 \%$ of fiber showed a drastic temperature rise at around 20 minutes, and exceeded the standard average temperature at around 90 minutes, and the standard highest temperature at around 30 minutes. It is believed that spalling took place, and the main reinforced bar was heated more based on the internal temperature.

\subsection{Test results of plastic viscosity of concrete}

To compare the pumpability performance of fiber reinforced concrete and Plain, mortar was collected by sifting it through a $5 \mathrm{~mm}$ sieve to measure shear stress and shear rate, and based on this the plastic viscosity was calculated, as shown in Figures 8 and 9 and Table 4.

Through the results the plastic viscosity of Plain was found to range between $0.858 \mathrm{~Pa} . \mathrm{s}$ and 0.873Pa.s, while the plastic viscosity of fiber reinforced concrete ranged between $0.863 \mathrm{~Pa}$.s and 0.881Pa.s, approximately 1 3\% higher, from which it was verified that plastic viscosity was slightly increased by the mix of fiber. The friction force between paste, fiber and mortar is believed to have been increased according to the mix of fiber.

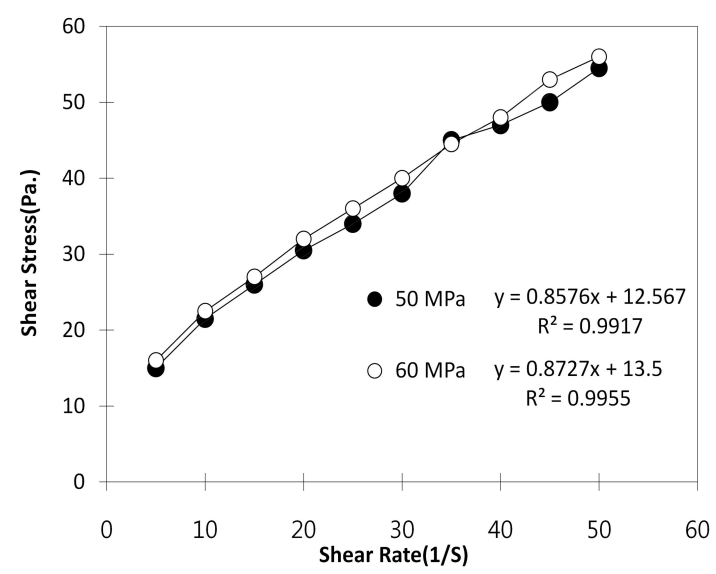

Figure 8. Correlation of Shear Rate and Stress I (Fiber Contents $0.00 \%$ ) 


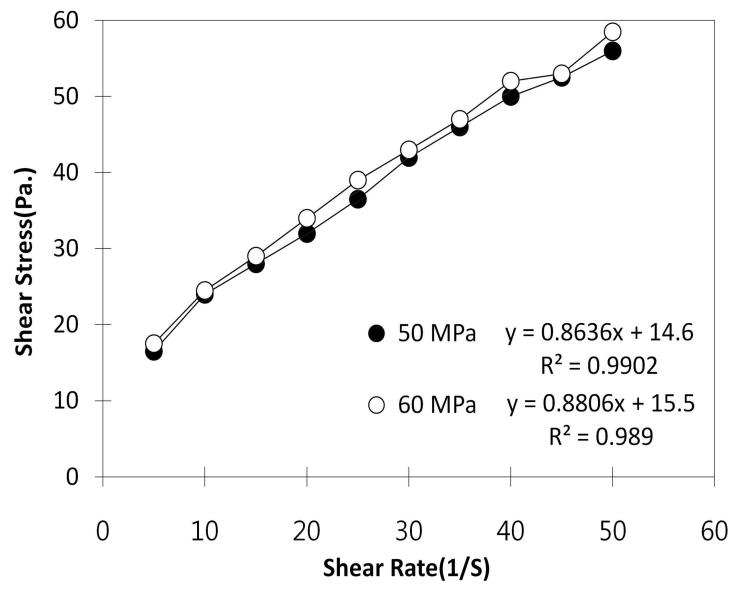

Figure 9. Correlation of Shear Rate and Stress ॥ (Fiber Contents $0.05 \%$ )

Table 4. Plastic viscosity of fiber reinforced and basic concrete

\begin{tabular}{ccccc}
\hline $\begin{array}{c}\text { Classification } \\
\begin{array}{c}\text { (Fiber contents, } \\
\left.F_{\text {ck }}(\mathrm{MPa})\right)\end{array}\end{array}$ & $\begin{array}{c}\text { Correlation } \\
\left(\mathrm{R}^{2}\right)\end{array}$ & $\begin{array}{c}\text { Tendency } \\
\text { equation }\end{array}$ & $\begin{array}{c}\text { Plastic viscosity } \\
(\mathrm{Pa} . \mathrm{s})\end{array}$ \\
\hline & & & $\mathrm{y}=0.858 \mathrm{x}+$ & \\
$0.00(\%)$ & 50 & 0.9917 & 12.6 & 0.858 \\
& 60 & 0.9955 & $\mathrm{y}=0.873 \mathrm{x}+$ & 0.873 \\
& & & 13.5 \\
& & & $\mathrm{y}=0.863 \mathrm{x}+$ \\
$0.05(\%)$ & 50 & 0.9902 & 14.6 & 0.863 \\
& 60 & 0.9890 & $\mathrm{y}=0.881 \mathrm{x}+$ & 0.881 \\
& & & & 15.5 \\
\hline
\end{tabular}

\subsection{Results of pumpability test}

It is difficult to obtain a homogeneous plastic viscosity from fresh concrete since concrete is a heterogeneous mixture. In particular, it is difficult to secure homogeneity due to its internal aggregate. For this reason, the highest pressure and the number of cylinder strokes were measured when the cement was pumped through the $400 \mathrm{~m}^{-}$long horizontal pipe for the pumping test, and the cement pumping time was measured while the cement was discharged to a certain volume of tank through an end hose. Through the test results, the friction factors of Plain and fiber reinforced concrete were calculated, and the results are indicated in Table 5.

In the test results of Series III, the plastic viscosity was found to increase by about 1 3\% according to the mix of fiber. However, in the horizontal pipe tests, the plastic viscosity was found to increase by at least $3 \%$ and up to $10 \%$, based on which it is believed that the plastic viscosity was increased, the internal stress was increased by the more frequent collision and contact between particles, and the friction factor became greater as a result.

Table 5. Maximum pumping pressure and friction factor

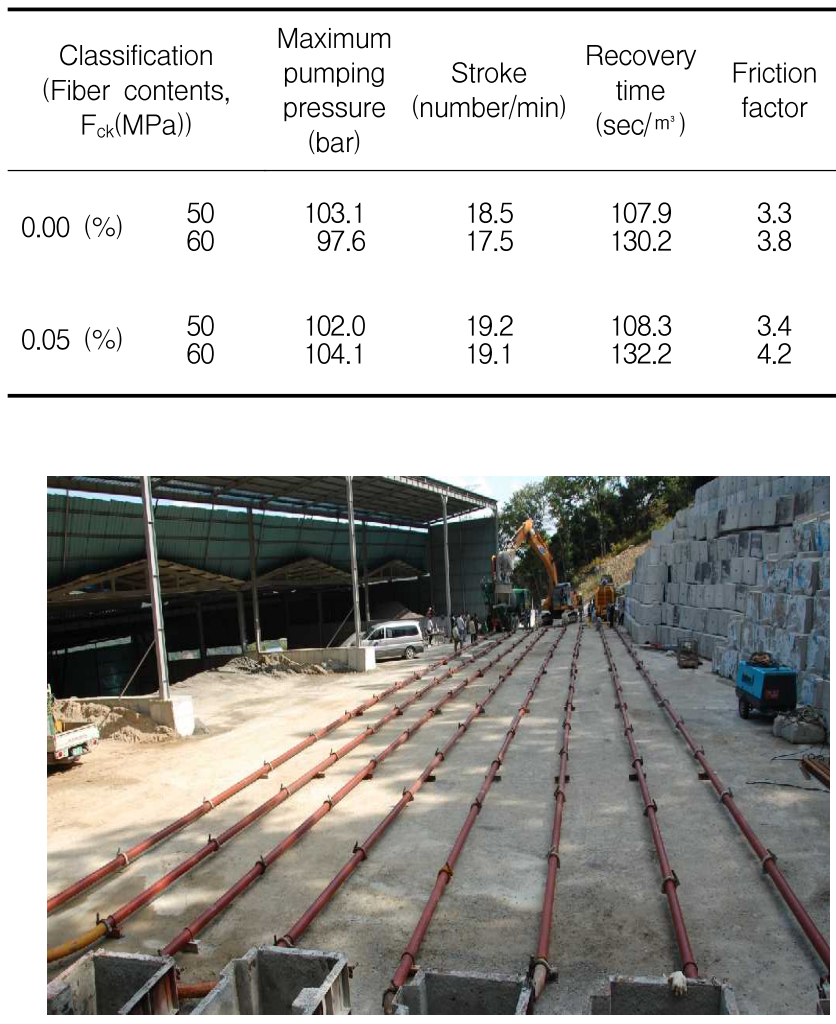

Figure 10. Horizontal pipe pumping test

\section{Conclusion}

In this study, the basic physical properties and fire resistance performance of fiber reinforced high strength concrete were examined, and the plastic viscosity properties of mortar collected from the concrete were also compared. In addition, the friction factor of high strength concrete was verified using a 400m-long horizontal pipe. The findings of this research are as below: 
1) In terms of slump flow, air content, and compressive strength, the fiber reinforced concrete showed a similar tendency to Plain, and polylon fiber had little impact on the basic physical properties of the concrete.

2) As the mix proportion of fiber increased, the average temperature and the highest temperature of the main reinforced bar was observed to be relatively low. The specimens with $0.05 \%$ and $0.075 \%$ fiber met the criteria announced by the Ministry of Land, Transport, and Maritime Affairs; however, the specimen with $0.025 \%$ fiber exceeded the standard temperature due to spalling. Thus, considering performance and economic feasibility, $0.05 \%$ fiber is believed to be advantageous.

3) In terms of plastic viscosity, the fiber reinforced concrete had 1-3\% higher plastic viscosity than Plain. The fiber is believed to have affected the friction factor of concrete, which led to a slight increase in plastic viscosity.

4) Through a $400 \mathrm{~m}-$ long pipe pumping test, the friction factor was calculated as between 3.8 and 4.2 in fiber reinforced concrete, and as between 3.3 and 3.4 in Plain. The friction factor increased by about 3 10\% in fiber reinforced concrete, and the fiber mix had an effect on friction factor and pumpability.

In a nutshell, the fiber mix had little effect on the basic physical properties of high strength concrete, but rather highly affected plastic viscosity and pumpability performance. Diverse data should be accumulated through subsequent and further studies in the future to apply fiber reinforced high strength concrete to construction sites.

\section{References}

11. Kim YR, Song YC, Jung YH, Kim OJ, Lee DB. An experimental study on the fire resistance properties of high strength concrete using fibre for field application. Proceedings of the 15th Autumn of Korea Institute of Building Construction; 2008 November 14; Pusan (Korea). Seoul (Korea): Korea Institute of Building Construction; 2008. p. 187-91.

12. Song YC, Kim YR, Kim OJ, Lee DB. Evaluation of fire performance for high strength concrete mock-up column with fiber by unloaded fire test. Proceedings of the 17th Autumn of Korea Institute of Building Construction. 2009 November 14; Cheongiu (Korea). Seoul (Korea): Korea Institute of Building Construction; 2009. p. 97-100.

13. Song YC, Kim YR, Oh JK, Kim OJ, Lee DB, Ko CH. An experimental study on fire resistance performance of high strength concrete by fiber contents and depth of concrete cover. Proceedings of Architectural Institute of Korea. 2009 October 23; Kangwon (Korea). Seoul (Korea): Architectural Institute of Korea; 2009. p. 583-6.

14. Han CG, Han MC, Heo YS. New proposal for spalling mechanism in high strength concrete. Journal of Architectural Institute of Korea. 2007 November; 23(11):109-17.

15. Son HJ, Han CG. Fire resistance performance review of high strength concrete structure mixing with the polylon fiber. Journal of Architectural Institute of Korea. 2010 April;54(6):46-8.

16. Pierre K, Gregoire C, Christophe G. High temperature behaviour of HPC with polypropylene fibers from spalling to microstructure. Cement and Concrete Research. 2001 October;31:1487-99.

17. Seo I, Lee HS, Park HG, Kim WJ. An experimental study on correlation between rheological parameter of picked mortar and fluidity of concrete from 30 to $150 \mathrm{MPa}$. Journal of Architectural Institute of Korea. 2009 September;25(9):93-100.

18. Kwon HW, Bae YK, Lee JS, Kim SI, Kim HS, Lee JS. The experimental study on the coefficient of friction change tendency which it follows in kinds of concrete strength and pumping pressure grade. Proceedings of the 16th Spring of Korea Institute of Building Construction. 2009 May 23; Seoul (Korea). Seoul (Korea): Korea Institute of Building Construction; 2009. p. 69-73.

19. American Concrete Institute Committee. ACI manual of concrete practice. American Concrete Institute; 2012. ACI 304.2R-96. Farmington Hills Michigan U.S.A 
20. Kim JW, Kim SM, Park YH. The world's longest distance ultra-high strength concrete pumping monitoring and integrated risk control technology development. Korean Journal of Construction Engineering and Management 2010 August;11(4):30-3. 